\title{
Distribution of Aortic Arch Collaterals in Rabbit
}

\author{
Dalma CSIBI ${ }^{1}$, Cristian MARTONOS ${ }^{1}$, Cristian DEZDROBITU ${ }^{1}$, Vasile RUS ${ }^{1 *}$, Flavia RUXANDA ${ }^{1}$, Viorel \\ MICLĂUŞ ${ }^{1}$, Aurel DAMIAN ${ }^{1}$ \\ ${ }^{1}$ University of Agricultural Sciences and Veterinary Medicine, Cluj-Napoca, Romania. \\ Corresponding author: vasilerus2002@yahoo.com \\ Bulletin UASVM Veterinary Medicine 72(1) / 2015, \\ Print ISSN 1843-5270; Electronic ISSN 1843-5378 \\ DOI:10.15835/buasvmcn-vm: 10552
}

\begin{abstract}
The stratigraphic dissection of the thorax and ventral cervical region was made on 5 rabbit cadavers. We firstly exposed the heart, and then the aortic arch. The aortic arch has a very curved trajectory and two collaterals (brachiocephalic trunk and left subclavian artery). The brachiocephalic trunk bifurcates in two collaterals (left and right common carotid arteries) and it ends with the right common carotid artery. The bicarotid trunk is absent in leporidae. In subjects taken into study, the diameter of the right subclavian artery (collateral of the brachiocephalic trunk) is larger than the one in the right common carotid artery (terminal of the brachiocephalic trunk).
\end{abstract}

Keywords: aortic arch, collaterals, rabbit.

\section{INTRODUCTION}

Aortic arch collaterals present a large variability regarding their origin, trajectory, diameter and distribution in animals (Damian, 2001; Barone, 2006; Paryani, 2012). In horses and ruminants, the aortic arch presents only one collateral: the brachiocephalic trunk (Damian 2001). Its collaterals are: left and right subclavian arteries and bicarotid trunk. After a short course, the bicarotid trunk bifurcates in the two common carotid arteries, left and right. Paryani et al. (2012) sustain that in the case of leporids, carnivores, swines and guinea pigs, the brachiocephalic trunk and left subclavian artery detach from the aortic arch, while Aydin et al. (2013) describe the brachiocephalic trunk, left common carotid artery and left subclavian artery as collaterals of the aortic arch in mole (Spalax leucodon).

\section{AIMS AND OBJECTIVES}

This research proposed to study the aortic arch collaterals, topographically, in rabbit and intercepting some variabilities of the origin of each studied vessel, depending on the subject.

\section{MATERIALS AND METHODS}

In this study, the cadavers of 5 half-breed rabbits were used, weighing between 2,5 and 3 kilograms. A longitudinal incision of the skin from the intermandibular area to the xiphoid appendix was made. Afterwards, the subcutaneous connective tissue was dilacerated and the chondrocostal articulations were sectioned, followed by the stratigraphic dissection of the thorax and ventral cervical region.

\section{RESULTS AND DISCUSSION}

The heart and origin of the large vessels were highlighted at macroscopical examination, after the stratigraphic dissection. Thus, the ascending segment of the aorta, aortic arch and pulmonary trunk were exposed. The aortic arch presents a very curved trajectory. It has two collaterals and continues with the thoracic descending aorta. The most developed collateral of the aortic arch is the brachiocephalic trunk. The second collateral of the aortic arch is the left suclavian artery. It emerges at a distance of approximately $4 \mathrm{~mm}$ from the emergence of the brachiocephalic trunk. The left 
subclavian artery has a mediolateral trajectory towards the cranial edge of the first rib pair, after which it continues with the left axillary artery.

The brachiocephalic trunk has a cranial trajectory, towards the cranial aperture of the thoracic cavity, where it continues with the right common carotid artery.

The first collateral of the brachiocephalic trunk is the left common carotid artery. It emerges at a small distance after the brachiocephalic trunk's origin and has a cranial trajectory.

The second collateral of the brachicephalik trunk is the right subclavian artery. It originates in the proximity of the cranial edge of the first rib pair, at a small distance to the right common carotid artery's origin. The right subclavian artery has a mediolateral trajectory and it continues with the right axillary artery from the cranial aperture of the thoracic cavity.

The aortic arch in rabbit is very curved, a lot more curved than in other species, aspect which is sustained by Barone (1996). The aortic arch has only one collateral in the majority of species (brachicephalic trunk), but in leporidae it has another collateral (left subclavian artery). Damian (2001) describes the presence of two collaterals of the aortic arch in carnivores and swines.

There were no variabilities regarding the origin of the vessels in subjects taken into study, but we observed the fact that the second collateral of the brachiocephalic trunk (right subclavian artery) has a larger diameter (approximately with $1 / 3$ ) in comparison with its terminal artery (right common carotid artery).

One thing that's worth noting is that in rabbits, the bicarotid trunk is not present because of the emerging point of the left common carotid artery. Likewise, the bicarotid trunk is absent in swines, carnivores, cetaceans and humans (Barone, 2006).

\section{CONCLUSIONS}

In leporidae, the aortic arch has a very curved trajectory, and presents two collaterals: the brachiocephalic trunk and the left subclavian artery.

The left subclavian artery detaches from the aortic arch at approximately $4 \mathrm{~mm}$ from the brachiocephalic trunk's origin.

The diameter of the right subclavian artery is approximately with 1/3 larger than the one of the right common carotid artery.

Acknowledgements. This paper was published under the frame of European Social Fund, Human Resources Development Operational Programme 2007-2013, project no. POSDRU/159/ $1.5 / \mathrm{S} / 136893$

\section{REFERENCES}

1. Aydin ZE, Ilgun R Ozkan (2013). The morphology of the arteries originating from the arcus aorta and the branches of these arteries in mole-rats (Spalax leucodon). Veterinarni Medicina 58(7): 373-376.

2. Barone R( 1996). Anatomie compare des mammiferes domestiques. Angiologie. Editions Vigot.

3. Damian A (2001). Anatomie Comparată, Sistemul Cardiovascular. AcademicPres, Cluj-Napoca.

4. Paryani Reza Mohammad, Hassan Gilanpour, Somaye Hamedi, Vorya Tohidi, Soroush Mohit mafi, Seyed Mehdi Rajaei, Reza Sadjadi, Mahdi Khademlo (2012). Scholars Research Library. Annals of Biological Research 3(9):4535-4541. 